\title{
The Use of Overseas Central Cataloging in Australia with Special Reference to Library of Congress Cataloging
}

BY JOHN METCALFE

LIBRARY OF CONGRESS cataloging as a form of central cataloging has taken the place of British cataloging in British countries, and in particular Australia. It is, however, one library's cataloging, and on the all important subject cataloging or information retrieval side, in its subject headings and their arrangement, it is, in its own words, "the product of evolutionary forces" from 1897 to date. Not all its headings are the fittest to survive; they are not evenly up-to-date in choice, and they are inconsistent in form, so that for information retrieval they are a functionally inferior mixture.

This paper does not propose to be an exhaustive proof of these propositions, nor is it the result of an exhaustive study; it is rather evidence that there should be one-constructive as well as destructiveof by-product central cataloging becoming the cataloging not only of libraries in its own country, not only of libraries fairly contemporary with it, but also of new libraries-new bottles in which the old wine turned to vinegar is being increasingly poured; of libraries in foreign countries (which are however close, "free world" allies of America in every respect).

In two books, one 1957 and one 1959, both published in America, the writer attempted a more general and exhaustive study, mainly at the technical level; in this he found far more fault with other
Mr. Metcalfe is University Librarian, University of New South Wales. His paper is here reprinted with permission from Seminar on Technical Services, Baillieu Library, University of Melbourne, 17-18 August, 1961, directed by Maurice F. Tauber, edited by Ira D. Raymond. (Canberra: Australian Advisory Council on Advisory Services, 1962.)

cataloging methods than he did with those of LC and said somewhere in it that LC cataloging should be criticized, not because it is bad, but because it is so good, with so much achievement and so much promise, so widely found useable and used; whereas most of the panaceas which are its competitors have got little further than boast and ballyhoo-in which LC does not indulge- even in its own country. Of course LC cataloging as central cataloging is not that of a system under one authority. It is of the take it or leave it kind, you don't have to take it if you don't want to, not even in America. It is offered and taken, but not with clear explanation or understanding of just what it is; not with enough caveat emptor, yet with immense prestige and authority of a moral kind. The allegations being made cannot only be of foreign interest, but the writer is not telling Americans-it would be impertinent of him to do so-and opinion of the relevance to the home situation of what he has to say must be entirely their own. 
The BM Catalogue in its still latest complete edition, in volumes, was once much used in some Australian research and reference libraries, both university and public. In one in which I worked, constant reference to it in a recataloging program was, I think, a strong influence in giving the new catalog a bibliographical bias, and in drawing interest and attention away from the essential indexing function of a library catalog, especially on the subject side. Being only an author catalog it was no use on the subject side; it is not linked with the library's subject index by any tracing notes, and this is only in quinquennial cumulations without any current supplementation. Also it is alphabetico-classed, whereas subject cataloging in Australia as in America is mainly alphabetico-specific, more or less based on Cutter's Rules. Even at the time when British and BM Catalogue influence were at their height the ALA subject headings list was a tool, at least for reference, although Australia had produced one of its own in 1896 (with a fourth edition in 1902 ) in H. C. L. Anderson's Guide to the System of Cataloguing, of the Public Library of New South Wales. In 1934 Charles Martel told me that this list, and Anderson's 101 rules had been used in the formative years of the present LC catalog.

We knew of the current availability of LC cards, but thought of them as printed cards, not as a subject cataloging service, and made little or no use of them. We were not able to accommodate a depository set anywhere in the country although one stood on offer to us. The first LC influence on our cataloging was through its published headings list. I was at the reference desk but had become interested in subject cataloging, and I well remember first coming across headings with round bracketed qualifications, where I would have expected just phrases or subheadings in our catalog, and, horror of horrors, an upward see reference, from specific to general.
I traced these innovations to their source and found, as happened increasingly, that a cataloger laudably eager for turnover or put-through had found a secret or private weapon not in general use; but I could not make my point that there should be-and had been in our catalog-entry which, if it was not always as specific as it could have been, was at least not explicit class entry with upward reference, and a consistency of form and function or logic in headings on which arrangement or filing depended, and on which in turn indexing efficiency depended, and that LC practice cut across all this. Apart from being put in my place, I was met with counter-argument, which has been used in America, that the dictionary catalog is illogical, and anyway the public doesn't understand. Of course alphabetical arrangement is not illogical for its own purposes. It is a perfect form of classification, as Jevons pointed out in 1873 , and it will allow-even with specific entry - of very useful classified suborders in its arrangement. The LC rules or arrangement are based on this, but the possibilities are largely nullified in its own cataloging by the formal inconsistencies of its headings. As for the public not understanding, I usually found this to mean that the catalogers do not understand a relation of form of headings and their arrangement which would benefit users even though they were not aware of its logical basis.

LC cataloging is like that of any old established card catalog, only more so than most, and what is wrong with its byproduct central cataloging is the inconsistencies that come with the cumulation, which is the only virtue of the card catalog. Even this might not be so bad if the results were sufficiently understood but its own explanation in its introduction to its headings list is not read, or if it is, it is too guarded and not explicitly enough a warning. In consequence new editions of the list are assumed to be 'updated,' somewhat as the sixteenth edition of DC 
is, and the list is taken as an ideal one, issued as such by a great authority. A very leading American librarian, in administration, once assured me that there could not be any inconsistencies in the list, and that if only he could get hold of his head cataloger and it was a weekend or holiday, she would be able to explain to me just how consistent were such headings as Artificial flowers, and Flies, Artificial; Animals, Legends and stories of, and Birds-Legends and stories. Another leading librarian who had worked in LC freely admitted the inconsistencies, which are going directly into comparatively new catalogs, or indirectly through the Sears popular abridgment of the LC headings, or through local central cataloging.

The use of cataloging aids is promoted by patriotism or feeling for another country which is at least neutral-not definitely hostile-but these are not enough. The goods have to have a genuine selling point, and they have to be delivered. The old BM Catalogue had the very important selling point that up to a point it was complete in a set of volumes that did not take up the room of a card catalog; and it was delivered. I remember it in one cataloging room slowly but surely weighing a great revolving bookcase down through the floor, and in another filling a press and bound in kangaroo skin. When I told some American librarians about this, nearly thirty years ago, one asked if the volumes had pockets, and I have been grateful for the story ever since. Quite apart from any abstract loyalty, and veneration for a library that still had a name to conjure with, the BM Catalogue was there, to impress itself on every young librarian. But it was dating; a new edition was announced in a very promising prospectus, and we put our money on the line, but over decades it made little progress, and only recently it has been started all over again, in the way in which it should have been begun originally. And not only with this but other things there was an ever increasing gap, or vacuum, and America was filling it, whether we liked it or not; we did not have to be Americanized to have a use and a need for the Wilson indexes, the Engineering Index, and by far the most useful and used abstracts, Chemical Abstracts. The only headings lists we had with up-to-date subject coverage, though inconsistent forms, were LC and Sears.

The only new British attempt, and opportunity, was BNB, the British National Bibliography. This was, and is, a useful classified book selection aid, and in this respect it was better than any American offering until some years later; but as well as being promoted as this, and as British to the backbone-with an association with the British Museum which sounded to be more than it was-it was also promoted as a cataloging aid, as in effect the British answer to LC (as years earlier Brown's now dead subject classification was supposed to be the scholarly, scientific, and British answer to Dewey). Orthodox tracing notes to BNB entries, of both subject headings and class numbers, would have made them a cataloging aid for both the dictionary and the classified catalog, and with some initiative and organization on the part of the British Museum or BNB Council they could have been supported by a list of subject headings - a British list-or an arrangement might have been made to use LC headings. The writer advocated and begged for something like this, for the colonial dictionary catalog customers whose subscriptions were being solicited, but nothing of the sort was done. BNB was made what it still is, a propaganda instrument for very unorthodox and much questioned theories of classification and alphabetical indexing, based on class number analysis, and what may prove to have been the last opportunity of restoring British and British Museum prestige and usefulness in central cataloging for, at least, British Commonwealth countries was sacrificed to the enthusiasm of a few for a new panacea, out of which they still dream of extracting 
subject headings and references by their chain analysis of class numbers which have to be impossibly elaborated for no other purpose: whom the gods destroy they first make mad.

Despite British assumptions of its Americanization, Australia and its libraries still buy far more British than American published books, but the imprints in BNB itself show that an increasing proportion of British published books - and especially of those bought for reference and research libraries-is one of American books issued in both countries. These are of course cataloged by LC, and in addition LC catalogs books in English which are not American or British, which BNB does not do. It catalogs them, as well as other foreign books, in astonishing numbers, and with no longer the time lag which was once threatening its efficiency and its support. Its proof copy cards by air mail are now reasonably up-to-date book selection aids and they can be used in integrated processing from selection to dictionary cataloging, as BNB cards cannot be, so that it is becoming doubtful whether these are now worth getting by air mail.

These proof copy cards are only part of what may be called, on analogy with population explosion, a bibliographical explosion, or chain reaction, which began overseas from America with the general availability after the 1939-45 war of the LC catalog in volume form-only an author catalog — but with the familiar unit card tracing note, and a little later with current supplementation and cumulation in volume form. What the British Museum at first did not do-photoprint its catalog from its slip catalog - was done first by some enthusiasts and then by LC itself, from LC cards. LC cataloging was now in overseas libraries, and it was complete and up-to-date in ways in which $\mathrm{BM}$ or BNB cataloging were not intended to be. The situation of about thirty years earlier was more than reversed. LC cata- loging could be used to full advantage, but also it could be swallowed, hook, line and sinker. Not only the form of headings but also subject determination and heading assignment could be taken, uncritically, completely, from the tracing notes of LC entries, and by this we may in some important respects be sunk. The disease of LC headings, from being only sporadic, may become-may have already become-epidemic and pandemic with further risk that not only may the forms of LC headings be not as good as they might be, but in addition its determination of the subjects of particular books and its assignment of headings may not be as good, on the average, as they might be. The greatest danger of centralization and standardization becomes very real.

Many British librarians had always used standardization or uniformity in itself as an argument against it and so against centralized cataloging, but this was through years when their own diversity did not show up very well against American uniformity, and in any case uniformity itself is hardly a fault in this field any more than in book printing. The obvious danger, however, still flows from centralization-that if there are defects at the center then they are everywhereand here we have centralized cataloging in a rapidly increasing volume taken to or coming down from an international or supranational level, with the added dangers that the final source is one library in one nation with perhaps some cooperative control nationally but none internationally; and that the cataloging is not primarily central cataloging; as such it is simply byproduct cataloging, with its only justification in economy.

Now the question is, what damage, what amount or sum total of damage is being done, if any, and this question is put here rather than answered. In any assessment there must be either an assumption that what may be wrong should 
be righted at all costs, or an assumption that there is possibly some compensation in other directions and that the account must be balanced as one of profit and loss if there is profit or gain in having LC more or less uncritically copied; and there is some gain. A mere glance at what the other fellow has already done is helpful, even if we end in doing the opposite; if we go-as we may be justified in going - to the other extreme, local cataloging can be reduced to completely uncritical copying of central cataloging. There need not even be copying; ready-made cards complete with headings can be filed, and even this may be done mechanically according to some punching of the ready-made cards, with all the advantages of nutrition without mastication and health without exercise; the century old dream of central cataloging would be complete reality, perhaps, just as the manless missiles were raining down.

Just before his death in 1903 Cutter said in the Preface to the fourth and latest edition of his rules, "On seeing the great success of ... Congress cataloguing ... . I cannot help thinking that the golden age ... is over, and that difficulties and discussions which have furnished an innocent pleasure to so many will interest them no more." The end of an age, if it is ended, was not as close as he thought then but there is no doubt that the difficulties, real or imagined (or only difficult to insufficiently able and trained people) and the associated discussions with all their innocent pleasure have brought local or independent cataloging into disrepute and have come near to ending the halcyon days, willy nilly and at whatever cost to the functional as opposed to the processing efficiency of cataloging. In terms of the labor and the money that is in fact being allowed for cataloging even by an affluent society, and for librarianship, and bibliography, and documentation, and information retrieval altogether, there is a need and an insistent demand from ad- ministrators and purse-bearers for economy in the cataloging process.

Librarians reply that what is sometimes expected or supposed by laymen to be all that is really needed is not as simple as they think and not enough for functional efficiency, but most librarians themselves and many catalogers are in some agreement, and many are prepared to pay for processing economy a price in possible loss of functional efficiency which they may not look at closely. They may simply want to recommend themselves as administrators and budget-balancers, or may not themselves be professionally competent or experienced enough to know how bad or how good cataloging can be, and how. Cataloging is at the very heart of librarianship, and yet it has become a special mystery in more senses than one and many chief librarians or directors assert almost with pride that they know nothing about cataloging and cannot discuss the simplest problem in it without calling for their head cataloger, who in the management of his or her special domain can often rely on the boss's ignorance.

Cataloging is in large part a mystery, especially on the subject side, because it has not been much more than half solved with general agreement on the solution, or the teaching of it, and this is a major factor in the present situation. Despite the efforts of Cutter and others there is as yet no body of theory and practice which is generally accepted as the means of maximum efficiency. Bibliosophists cry lo here and lo there, with astrology where there should be astronomy and alchemy where there should be chemistry. Administrators and even catalogers are sceptical of what can so easily be dismissed as perfectionism. And an unfortunate conclusion may be drawn that many catalogers might as well be replaced by clerks just copying LC, because they have not been taught, or have not learned, principles on which to criticize and improve LC. Now, 
before drawing further conclusions, what sort of thing is supposed to be wrong with LC subject cataloging?

We can state very briefly as to subject determination and headings assignment, that the specific subject qualification or limitation of a book is not always clearly realized or distinguished, and to be on the safe side the cataloger has given the book too many entries, which reduces both processing economy and functional efficiency; that what has been called a fifth column in the catalog is common-that is, the use of title word entry instead of, or to supplement, proper subject entry, usually because there is not an appropriate heading already in the list and the process of getting a new one in is probably too troublesome and time consuming; it is not sufficiently realized that some catalogers in LC probably work to the list as it is, and make it a procrustean bed for their cataloging, just as half-trained, inexperienced local catalogers often do with the very much abridged Sears. As to the supposedly basic principle of its cataloging, there is considerable if not quantitatively important use of class entry with upward reference which reduces functional efficiency; for example, an inquirer looking under "Milk Substitutes" is referred to "Food Substitutes," and out of the many more entries under this he has to sort out those for literature on Milk Substitutes, which is not good information retrieval in a catalog which does distinguish about sixty kinds of dog and has at last got round to distinguishing some kinds of football as well as Soccer. As to the form of headings there are such inconsistencies as "Artificial Limbs," but "Eyes, Artificial"; "Agricultural Research" and "Agricultural Exhibitions," but "Agriculture -Competitions," and "ArchitectureExhibitions"; "Composition (Music)," but "Music-Interpretation"; "CatsLegends and Stories," but "Cats (in Religion, Folklore, etc.)" and "Cats in Literature," without the brackets. Such ex- amples could be multiplied by the hundred. They are not justified by usage, that is, by differences which the inquirer would expect and anticipate. They make for reduced economy in processing because they increase the number of cross references to be put in and the number of filing difficulties, and they reduce functional efficiency because they increase cross reference use, and reduce the subject or subject aspect grouping which is quite possible and allowable with specific entry - mainly by the use of subheadings -and is well established in its own headings.

Such inconsistencies are understandable and excusable in a large catalog with long cumulation and would be found in many smaller and younger catalogs. It is understandable that they are being copied into many smaller and younger catalogs when it is realized, first, that LC central cataloging, and its headings list as an aid, are only by-products of its cataloging of its own collections; and, second, that this central cataloging is only an unmodified by-product of its own cataloging and all the implications and consequences are not generally realized. We are getting highly centralized cataloging cheap, without realizing the price we may really be paying in the product. All these suggested defects in LC cataloging and its transmission as central cataloging may be quantitatively serious, or they may be only the magnification of a perfectionist riding a hobby horse, but their removal or reduction would mean some improvement in both processing economy and functional efficiency in cataloging based on that of LC. But how could they be removed or reduced?

LC cataloging is published for more purposes than central cataloging through copying, though this is a lot of the justification and use of its publication. But published bibliography with or without uses other than central cataloging need not be the cataloging of a particular li- 
brary, as that of BNB shows, but some association with a library can be useful, as BNB also shows; its cataloging is not done by the British Museum, but is done in it from the Museum's acquisitions, especially its copyright deposit acquisitions. The BM Catalogue and its Subject Index are certainly not BNB's Ranganathanite version of DC classified cataloging, but in their preparation some use may now be made of BNB entries. The point is that there may be economical advantage, and even necessity in some association of a large library and its acquisitions with centralized cataloging for other libraries, but there need not be identification of cataloging, either way.

The writer had something to do with another, far, far less important case than either LC of BNB. In this, central cataloging was done mainly but not entirely from a large library's own acquisitions, and this central cataloging was then modified in the library's own cataloging of those acquisitions. It had to be modified for the same reasons the other way round that LC cataloging needs modification; for example "Economics" was used as a heading in the central cataloging for other libraries but the central library was still using "Political Economy" as a heading because it had hundreds of entries under it. The central library's cataloging could have been modified for central cataloging, which would probably have been delayed by this order; or the central library's cataloging could have been published on the do-what-you-like-with-it principle, but this would have defeated the purpose of aiding comparatively inexperienced catalogers by giving them up-to-date headings and of checking the spread of infection from an old, long cumulated catalog. It may not be irrelevant to notice that some British librarians say that cataloging in their large urban and county library systems is primarily cataloging for branches - that the cataloging of the central reference library is often subordinated to this and made a mere makeshift adaptation of it. We must be careful to look both ways, and upwards and downwards, before stepping off the pavement we are on.

By-product central cataloging looks the cheapest, but even this may not be certain; two associated cataloging processes and two associated processing bodies, even though there is association and cooperation, appear to raise costs; but they also distribute costs and may reduce a deflection of one of the bodies from its original purpose. Whether justified by its original charter or not, the British Museum seems very wary of taking on what are now thought to be functions of a national library; the Library of Congress on the other hand has embraced those functions and may have given them their current definition but not without recurrent complaint that it is, after all, the $\mathrm{Li}$ brary of Congress. The setting up of a separate body of council for central cataloging - but working in close association with LC - might meet some of these complaints at what would be comparatively small cost, especially if the services rendered were not so much thought of as a by-product to be given away. The desire to give away, to help as freely as possible may have motivated and justified the byproduct line of thought and economy and at the same time made the thinkers blind to some of the by-products of the byproduct approach. For what the information may be worth, there is now in Australia an Advisory Council on Bibliographical Services which directs the work of, but does not administer a bibliographical center; this was in a parliamentary library which was also a national library on the LC plan but the two have been recently separated and the bibliographical center (with the same relation with AACOBS) is now in the National Library of Australia.

Central cataloging associated but not identified with that of a particular library 
can be more flexible, directed to and even varied according to the needs of its users, but it must have a consistent practice or it will not avoid inconsistencies, partly caused-as LC says of its own headings - by "varying theories of subject heading practice over the years."

In the writer's view, and of course he is not alone, a new body of theory and practice must be laid down and taught not only as the basis for the specific entry of the dictionary catalog, divided or undivided, but also as the basis of any indexing or information retrieval. He does not accept the view that documentation or information retrieval must be, or is, essentially different from library subject cataloging, but he does think that librarians who have neglected their own half-solved problems of cataloging are at least as much to blame for the opposition of information retrieval and library cataloging as the amateurs, the engineers, and the chemists are, with their usually ignorant and prejudiced assumptions of what is covered by the word cataloging. $\mathrm{He}$ is sceptical of theorizing with little relation to the proven theory and practice of the past, and of new names for old things such as documentation and information retrieval for subject indexing, descriptors for subject headings, and so on; he thinks Cutter in his specific entry definitions and rules and Kaiser with his concrete-process breakdown made permanent progress, independently but essentially on the same lines. Theirs were major steps towards logical subject indexing, whether mechanized or not, and whether arrangements of subject names such as theirs are used directly or indirectly.

Cutter's theory and practice was exemplified in LC cataloging in its subject headings, though with some unexpected deviations from the master. The writer thinks a development of Cutter's practice, and Kaiser's, should be exemplified in an ideal subject headings list, the compilation of which would be the inductive corrective of the deductive approach, from principles. But this would be detail at the technical level. The cataloging in question is American, and even as it isthough we may receive it critically-we receive it with admiration and gratitude. Whatever might be done to improve it would have to be done in America, and whatever is done or not done, we hope that we may continue to receive it with admiration and gratitude.

\section{Information Centers ...}

(Continued from page 12)

comparative study of alternative approaches. Without comparative studies it is not possible to demonstrate objectively the practicability of any system.

Finally, the study underscored the importance of administration. An information center, like any other organization, is subject to the principles of administration. While this is axiomatic, and certainly not startling, its importance has again been demonstrated. In the absence of sound administration, it will be difficult, if not impossible, to blend the varied skills described above into an integrated, effective organization. 